The Role of Property Rights in Bycatch Reduction: Evidence from the British Columbia Groundfish Fishery

\author{
Tonya Edinger \\ Department of Economics \\ School of Management \\ University of Alaska, Fairbanks \\ Email: tmedinger@alaska.edu
}


Advisory Committee:

Dr. Douglas Goering

Dr. Jungho Baek

Dr. Joe Little, Advisory Committee Chair

Dr. Joe Little, Resource \& Applied Economics Program Director 


\title{
The Role of Property Rights in Bycatch Reduction: Evidence from the British Columbia Groundfish Fishery
}

\begin{abstract}
The following analysis seeks to contribute to the literature by examining the effectiveness of the individual vessel bycatch quota (IVBQ) system as an incentive structure for the mitigation of halibut bycatch in the British Columbia Groundfish fishery. Through the use of an OLS regression technique, this empirical analysis intends to quantify the importance and overall effectiveness of the vessel bycatch quota incentive system in respect to mitigating bycatch. The research utilizes time series fisheries data from 1962-2012, as provided by The International Pacific Halibut Commission and Fisheries and Oceans Canada. The research indicates that the IVBQ system has proven to be highly effective, confirming the significance of private property rights as a tool for the reduction of bycatch within British Columbia. Policy makers may utilize the information provided in this paper to design more feasible and effective policy options to promote the preservation of ecological balance in the management of marine resources.
\end{abstract}




\section{Introduction}

Oceans cover the majority of the Earth (71 percent) and are considered to be a common pool resource (Pinkerton, 2009). The oceans' fisheries provide a vital protein source for the world's population. Yet when a resource belongs to everyone, it belongs to no one. The implications of common pool resources are widespread and are particularly applicable to the world's fisheries. The simplest fishery model is that of open-access, containing no barriers to entry or fishing effort restrictions. The open-access model suggests that lucrative fisheries will attract increased fishing pressure until stocks are depleted and profit levels are similar to alternative opportunities. Without supplemental incentives, fishermen have little motivation for long-term investment in the fishery (Schlager et al, 1999). The incentive structure is such that the fishermen will increase fishing effort and continue to reap the benefits while the negative consequences of the resource depletion are dispersed amongst all stakeholders. Various marine policies have responded in attempts to avoid this tragedy of the commons scenario (Hardin, 1968).

Initially proposed by Moloney and Pearse (1979), market-based tools and privatization of access and withdrawal rights were first implemented in New Zealand and Iceland in the 1970s. Individual Transferable Quotas (ITQs) are used to establish a maximum limit on the quantity of fish that can be withdrawn by each vessel. This transferrable economic tool creates a market for the quotas and is specifically intended to internalize the negative externality of resource exploitation and degradation. ITQs intend to increase economic rents, increase safety due to increased flexibility, reduce overcapitalization and provide better product quality. The use of ITQs has become increasingly prevalent within present-day marine resource management regimes and the quota system has proven to be largely effective in providing an incentive framework to promote sustainable management of single species fisheries (Costello et al, 2008). 
Yet these advantages are paired with tradeoffs. The basic ITQ incentive structure tends to promote stewardship of a single-species at the expense of multi-species interactions; the ITQ system does not necessarily encourage fishermen to attend to habitat linkages (Pinkerton, 2009). Despite the proven effectiveness of ITQs for managing single-species fisheries, previous empirical studies have not yet reached a definite consensus specifying the ecosystem impact of an ITQ system. The quotas themselves are often criticized for their neglect of these complex multi-species interactions. In some cases, an increase in discarding and illegal fishing has been reported. Despite various theoretical claims, the complexity of the interactions has caused the relationship between ITQs and the broader ecosystem to remain relatively ambiguous.

Our empirical analysis will focus on the British Columbia Trawling Groundfish fishery, Area $2 \mathrm{~B}$, and the innovative implementation of an individual vessel bycatch quota system to manage incidental catch (Figure 1). Incidental catch (or "bycatch") is defined as "fish which are harvested in a fishery, but which are not sold or kept for personal use, and includes economic discards and regulatory discards" (Devido, 2006). Groundfish trawling is a nonselective harvesting technique and, due to ecological interdependence, fishermen are likely to harvest Pacific Halibut (Hippoglossus stenolepis) although Groundfish are the targeted species catch. Joint harvesting presents fishermen with a complex set of trade-offs as the optimal exploitation of one stock will rarely result in the optimal harvesting of another. Abundant species are inevitably found to be mixed with overfished species presenting significant challenges to fishing vessels. Pacific Halibut weigh in at an average of five hundred pounds and can measure nearly eight feet in length. The Pacific Halibut are migratory in nature and span the Pacific coast as seen in Figure 2. When halibut are incidentally harvested in the Groundfish fishery, they do not have an economic value although the species is quite valuable elsewhere. The trawling industry in 
general is a low value, high volume fishery with limited capability for adaptation to higher costs or lower prices. Moreover, the trawl sector is the largest fishing sector in the province of British Columbia in terms of catches, revenues, and employment on boats and within processing plants. British Columbia's coastal communities are becoming increasingly dependent on Groundfish trawling operations. Correspondingly, any decreases in total allowable catch (TAC) for the purpose of reduced bycatch tend to put the communities at financial risk (GSGislason, 2010). As a result of the previously mentioned factors, the bycatch problem is both economic and ecological in nature.

An ITQ system was implemented within the British Columbia Groundfish fishery in the year 1990. The ITQ system establishes quasi-property rights and the quotas are designated as a percentage of the variable total allowable catch. The ITQs were based $70 \%$ on catch history and $30 \%$ on vessel length. The British Columbia Groundfish fishery subsequently implemented an individual vessel bycatch quota (IVBQ) system in 1996 in order to mitigate bycatch and effectively promote the preservation of ecological balance in the management of marine resources. Each of the limited entry Groundfish trawl license holders receives an individual vessel bycatch quota that represents a percentage of the species-specific TAC. The IVBQ allocation is formulated based on both vessel catch history as well as the length of the vessel. The province has found full on-board observer coverage (100 percent) to be economically viable for regulation purposes. In addition to full observer coverage, the British Columbia Groundfish fishery deducts mortality of marketable fish from quotas (GSGislason, 2010). Vessels must immediately cease fishing operations upon fulfilling the quota limit. A quantitative analysis detailing the effectiveness of the policy change (individual vessel bycatch quotas) in British Columbia has not yet been conducted as most analyses have taken qualitative approaches. The 
econometric model seeks to provide empirical evidence to support the existing qualitative research foundation, further indicating that the use of the specified market-based tool promotes individual accountability with respect to multi-species stewardship.

\section{The model and the method}

In quantifying the overall effectiveness of the individual vessel bycatch quota (IVBQ) system as an incentive structure for the mitigation of bycatch, we consider the following equation:

$$
\log (H I C)=\alpha_{0}+\delta_{1} I V B Q+\delta_{2} \text { Biom }+\delta_{3} \text { Hallan }+\delta_{4} I T Q+\mu_{t}
$$

where $H I C_{t}$ is the total halibut incidental catch within British Columbia fisheries; Biom ${ }_{t}$ is the total pacific halibut biomass; Hallan is halibut landings or the amount of halibut that are harvested; $I V B Q_{t}$ is a dummy variable capturing the IVBQ impacts, which is the variable of primary interest - taking on a value of 0 if the year is before 1996 when the IVBQ was not implemented, and equals 1 if the year is 1996 or later; $I T Q_{t}$ is a dummy variable quantifying the effect of the Individual Transferrable Quota (ITQ) system within the Groundfish fishery - taking on a value of 0 if the year is before 1990 when the ITQ was not implemented, and equals 1 if the year is 1990 or later; and $u_{t}$ is the error term. If an increase in halibut biomass causes an increase in permitted halibut fishing and hence a decrease in incidental bycatch, an estimate of $\beta_{1}$ is expected to be negative. If an increase in halibut landings leads to a rise in halibut bycatch, an estimate of $\beta_{2}$ is expected to be positive. If the IVBQ system leads a decrease in halibut incidental catch, an estimate of $\beta_{3}$ is expected to be negative. Finally, if the ITQ system within 
the Groundfish fishery causes halibut bycatch to decrease, the estimate of $\beta_{4}$ is expected to be negative.

\section{Data}

Annual data for the period 1962-2006 is collected for empirical analysis. The data time span is chosen based on availability of all data. The total halibut incidental catch within British Columbia fisheries is obtained from the International Pacific Halibut Commission's working reports. The total Pacific halibut biomass is used as a proxy for changes in Pacific halibut stock population and is taken from the International Pacific Halibut Commission. The halibut landings or the amount of halibut that are harvested are used as a proxy for fishing pressure on the halibut populations and is collected from the Sea Around Us Project at the University of British Columbia Fisheries Center. The data is summarized in Table 1 below.

Table 1: Descriptive Statistics

\begin{tabular}{lrrrr}
\hline Variable & Mean & Std Dev & Min & Max \\
\hline Year & 1984 & 13.13 & 1962 & 2006 \\
HIC & 1213.27 & 629.036 & 177 & 2183 \\
IVBQ & 0.33 & 0.48 & 0 & 1 \\
Hallan & 11154.67 & 3861.79 & 4474 & 17473 \\
Biom & 54.90 & 18.70 & 29.35 & 86.9 \\
IIC & 6.86 & 0.82 & 5.18 & 7.69 \\
\hline
\end{tabular}




\section{Empirical Analysis}

\begin{tabular}{|l|l|}
\hline \multicolumn{2}{|c|}{ Table 2: Initial Regression Results [T=45] } \\
\hline Dependent Variable: $\log (\mathrm{IC})$ \\
\hline$\beta_{0}($ Constant $)$ & $\begin{array}{l}7.227 * * * \\
(.265)\end{array}$ \\
\hline$\beta_{1} I V B Q$ & $\begin{array}{l}-1.310^{* * *} \\
(.348)\end{array}$ \\
\hline$\beta_{2}$ Biom & $\begin{array}{l}.0218^{* * *} \\
(.00625)\end{array}$ \\
\hline$\beta_{3}$ Hallan & $\begin{array}{l}-.00000937 * * * \\
(.0000242)\end{array}$ \\
\hline$\beta_{4} I T Q$ & $\begin{array}{l}-.210 \\
(.374)\end{array}$ \\
\hline $\mathrm{R}^{2}$ & .719 \\
\hline$* * *$ and $* * *$ denote respective significance levels at the 10,5 and 1 percent level. \\
\end{tabular}

The initial regression yields seemingly favorable results, outlined in Table 1. Most of the independent variables are statistically significant at the $1 \%$ level and the $\mathrm{R}^{2}$ is relatively high at .719. Yet, the large $\mathrm{R}^{2}$ and $\mathrm{t}$ statistics act as a warning sign, potentially indicative of serial correlation. The statistical insignificance of the ITQ policy change is also puzzling. Within this initial regression, it would appear that the IVBQ policy change, ceteris paribus, results in a decreased amount of bycatch. Yet we must further refine the model before moving forward with any concrete inferences. In the presence of serial correlation, the t-statistics are not valid for inference.

Within the specified model, the independent variables are not assumed to be strictly 
exogenous. As a result, we cannot utilize the Durbin-Watson statistics to test for serial correlation. An alternative test for AR(1) serial correlation without strictly exogenous regressors involves running the OLS regression and obtaining residuals, then estimating the effect of the OLS residuals on all independent variables including the lagged residual. Upon estimation, $\rho$ is estimated as .675 . We soundly reject the null hypothesis $H_{0}: \rho=0$ in favor of $H_{1:} \rho \neq 0$ at the $1 \%$ significance level. As a result, we may conclude that there is strong evidence of AR(1) serial correlation in the errors. Unfortunately, the presence of serial correlation means that the $t$ statistics for the estimated coefficients we obtained before are not valid for inference. Since we've detected serial correlation within the model, we must correct for it. Before doing so, it is important to test the data to determine if the data follows a stationary stochastic process.

We use both the Augmented Dickey Fuller test and the Elliott-Rothenberg-Stock DFGLS test to determine if the time series follows a unit root process. Both tests are utilized as the DF-GLS test is intended to be an improved version of the Augmented Dickey-Fuller test and it has the best overall performance in terms of small sample size and power (Elliot et al, 1996). In this case, it is important to specify lags in order to clean up any serial correlation (Wooldridge, 2009). Due to the small sample size, a large amount of lags is unfavorable. Yet it is important to include a sufficient amount of lags in order to completely model the dynamics. The lags were chosen based upon the Schwert Criterion (1989) of $\operatorname{pmax}=\left[12^{*}(\mathrm{n} / 100)^{1 / 4}\right.$. Based on the sample size, 9 lags were used. 
Table 2: Unit Root Tests- ADF and DF-GLS

Dependent Variable: $\log (\mathrm{dll} C)$

\begin{tabular}{|l|l|}
\hline ADF (no trend) & $\mathrm{t}=-2.407$ \\
\hline ADF (trend) & $\mathrm{t}=-3.049$ \\
\hline DF-GLS (no trend & $\mathrm{t}=-2.771$ \\
\hline DF-GLS (trend) & $\mathrm{t}=-2.771$ \\
\hline Lags are computed based on the Schwert Criterion of $\operatorname{pmax}=\left[12^{*}(\mathrm{n} / 100)^{1 / 4}\right.$. \\
\hline
\end{tabular}

Based on the results of the Augmented Dickey Fuller test and the Elliott-RothenbergStock DF-GLS test in Table 2, we cannot reject the unit root hypothesis; we do not have strong evidence to reject the null hypothesis of a unit root. Therefore, we may venture to conclude that the root process is integrated of order one, I(1). This data represents a non-stationary series and is referred to as a difference-stationary process. Unfortunately, the initial OLS estimates are not valid for inference. In order to obtain reliable estimates, we must use the first difference of this process. After the first-difference transformation has been performed, the series is classified as weakly dependent.

The equation must then be re-estimated using the Newey West standard errors. The Newey-West estimation produces consistent estimates when autocorrelation and possible heteroskedasticity is present. This will correct for apparent serial correlation as well. 


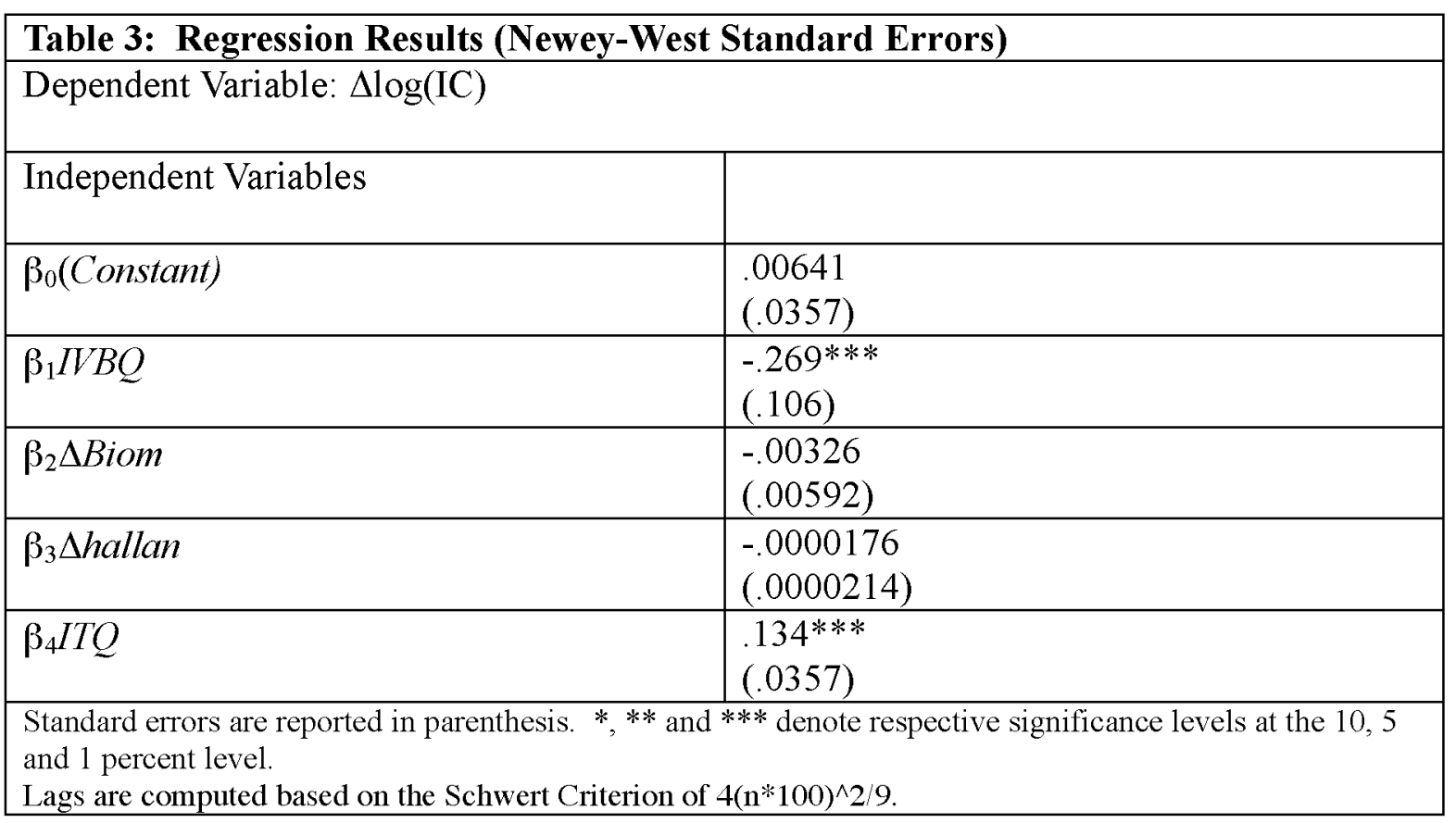

The results of the regression with Newey West standard errors portray a much different picture than the original regression. Our primary interest is the coefficient on the individual vessel bycatch quota (IVBQ) system as an incentive policy for the mitigation of bycatch. The coefficient of the dummy variable for the IVBQ is found to be negative, suggesting that the IVBQ system has a beneficial effect on reducing halibut bycatch in the long-run; for example, the IVBQ reduces incidental bycatch level by approximately $26.9 \%$ during the period $1996-$ 2006. This provides strong empirical evidence that the IVBQ is effective in mitigating bycatch. A possible explanation for this finding is that the IVBQ system creates a market for transferrable bycatch quotas and establishes property rights for incidental catch, which in turn alters fishermen behavior in favor of multi-species stewardship and hence reduces bycatch substantially. The variables Pacific Halibut biomass (Biom) and Pacific Halibut landings (hallan) are no longer statistically significant. Yet, the policy variables ITQ and IVBQ remain statistically significant 
at the $1 \%$ level. The first differencing hinders the ease of model interpretation, yet the results are still straightforward and confirm our expectations. With the implementation of the IVBQs, the difference in bycatch levels between year $t$ and the preceding year (t-1) is estimated to be $26.9 \%$. This provides strong evidence in favor of the IVBQ policy change and is consistent with the expected outcomes for the model. One would expect the incentive-compatible accountability system (IVBQs) to significantly decrease Halibut bycatch. The quotas create a market for transferrable bycatch quotas and establish property rights for incidental catch. The vessel bycatch quotas reduce bycatch by creating an institutional framework and incentive structure to alter fishermen behavior in favor of multi-species stewardship. The model results also indicate that bycatch is, in part, avoidable. Prior to the policy implementation, bycatch limits were enforced in an aggregate manner that would appear to be less incentive-compatible. The transferability of the quotas encourages high-bycatch fishermen to exit the market. The fishermen who remain are relatively more bycatch-conscious. The empirical results demonstrate that, given the appropriate incentives to avoid specific species and target another, fishermen are remarkably capable of adapting to a change in quota systems.

An independent dummy variable representing ITQs has been included within the analysis to control for the implementation of private property institutions. The ITQ variable proves to be positive and statistically significant at the $1 \%$ level in Table 3 . With the implementation of the ITQs, the difference in bycatch levels between year $t$ and the preceding year (t-1) is estimated to be $13.4 \%$ greater. As previously noted, the basic quota system does not provide an adequate incentive structure for multi-species interactions. Although it is now widely accepted that official fisheries management and regulation programs work better when they do not incentivize a "race for the fish", resource management specialists often cite the 
absence of a so-called "perfect technique" to do so. These professionals assert that management techniques may have advantages yet must all possess disadvantages. For instance, the tools “....will work well when conditions are right, but none will work well under all conditions." (Gulland 1989, p. 270) A "silver bullet" does not exist for fisheries management problems and, therefore, it is important that the regulatory instrument is designed carefully as a part of a broad ecosystem-based management scheme with the ultimate goal of conserving the resources, preserving supporting ecosystems and ensuring social justice in the use of these resources. Critics of ITQs have cited the inflexibility that the mandated quota system imposes. The results of the empirical analysis have demonstrated that the ITQ must be viewed as a part of a larger toolkit available to guide marine resource management and as one that will not always provide an ideal solution for effective marine stewardship.

In order to be successful, the IVBQs must be paired with a variety of other characteristics such as individual accountability, high observer coverage, enforcement, disincentives and overall flexibility of the system (DeVido, 2006). A key feature of British Columbia Groundfish fisheries is their high observer coverage. The cost of observer coverage is mandatory for all vessels and is paid for by the fishermen themselves. The fishermen are faced with two options for observer monitoring. Option A mandates 100\% observer coverage at the cost of CDN\$300/day (Grafton et al, 2005). On the other hand, Option B only requires observer coverage for 15 days out of the year (paid for by the government) yet catch limits are significantly restricted. Over $90 \%$ of the fleet chose to participate in option A, indicating that the behavior changes and costs associated with $100 \%$ observer coverage are favorable to the trade-offs associated with a reduced catch limit. 
In the presence of pooled bycatch quotas, fisheries tend to experience preeminent fishery closures as a result of attaining prohibited species catch limits, as is the case in the Alaska Groundfish fishery. The aggregate nature of the bycatch allowance does not provide adequate individual incentive to promote accountability for incidental catches. Moreover, the premature closure of a fishery is unfavorable to various stakeholders due to under-exploitation of economically valuable stocks. A quota system similar to that of British Columbia has the potential to assist in further reducing incidental catch within Alaska's Groundfish fisheries yet one must also consider key difference in the characteristics of Alaska fisheries when compared to British Columbia. For instance, within Alaska the observer coverage levels have not been altered since 1990 and observer coverage is not a requirement on vessel less than 60 feet in length.

The IVBQs can clearly not be viewed as a panacea for all fisheries bycatch problems yet the system has proven to be highly effective in the case of the British Columbia Groundfish fishery. Based on the results of the econometric model, British Columbia was able to effectively internalize the negative externality of incidental catch by assigning transferrable property rights to the resource in question. Despite their effectiveness in Canada, it is important that each fishery be evaluated on a case-by-case basis to determine if a similar system may prove effective. The bycatch reduction tool must work with the existing incentive structure. Moreover, each country and fishery already contains existing incentive structures, regulatory requirements and unique fishermen behavioral tendencies. Ultimately, the empirical analysis has provided constructive insights for the case of British Columbia yet limited conclusions for the widespread viability of the system. Further research detailing the tradeoffs associated with 
implementing property rights for bycatch in additional multi-species fisheries may prove to be insightful and valuable to comparable fisheries.

\section{Conclusions and policy implications}

The British Columbia Groundfish fishery implemented an individual vessel bycatch quota (IVBQ) system in 1996 to mitigate incidental bycatch and effectively promote the preservation of ecological balance in the management of marine resources. The previous analysis intends to quantify the effect of the IVBQ on incidental halibut bycatch, controlling for other relevant variables such as halibut biomass, halibut landings.

We have empirically found that the IVBQ system has proven to be highly effective in mitigating bycatch in the case of the British Columbia Groundfish fishery. This implies that British Columbia has been able to effectively internalize the negative externality of incidental bycatch by assigning transferrable property rights to the resource in question. The empirical evidence also brings into question the effectiveness of the basic ITQ incentive structure and its overall ability to effectively promote stewardship of multi-species interactions.

There are several marine policy implications relevant to these empirical findings. Primarily, given the ineffectiveness of the ITQ system as an adequate incentive structure for multi-species interactions, policy makers should understand that a "silver bullet" does not exist for fisheries management problems and, therefore, it is important that the regulatory instrument is designed carefully as a part of a broad ecosystem-based management scheme with the ultimate goal of conserving the resources, preserving supporting ecosystems and ensuring social justice in the use of these resources. Furthermore, despite their effectiveness in Canada, the IVBQs should clearly not be viewed as a panacea for all fisheries bycatch problems. Rather, it is important that each fishery be evaluated on a case-by-case basis to determine if a similar system may prove 
effective. The bycatch reduction tool must work with the existing incentive structure. Moreover, each country and fishery already contains existing incentive structures, regulatory requirements and unique fishermen behavioral tendencies. Ultimately, the empirical analysis has provided constructive insights for the case of British Columbia yet limited conclusions for the widespread viability of the system. Further research detailing the tradeoffs associated with implementing property rights for bycatch in additional multi-species fisheries may prove to be insightful and valuable to comparable fisheries. 


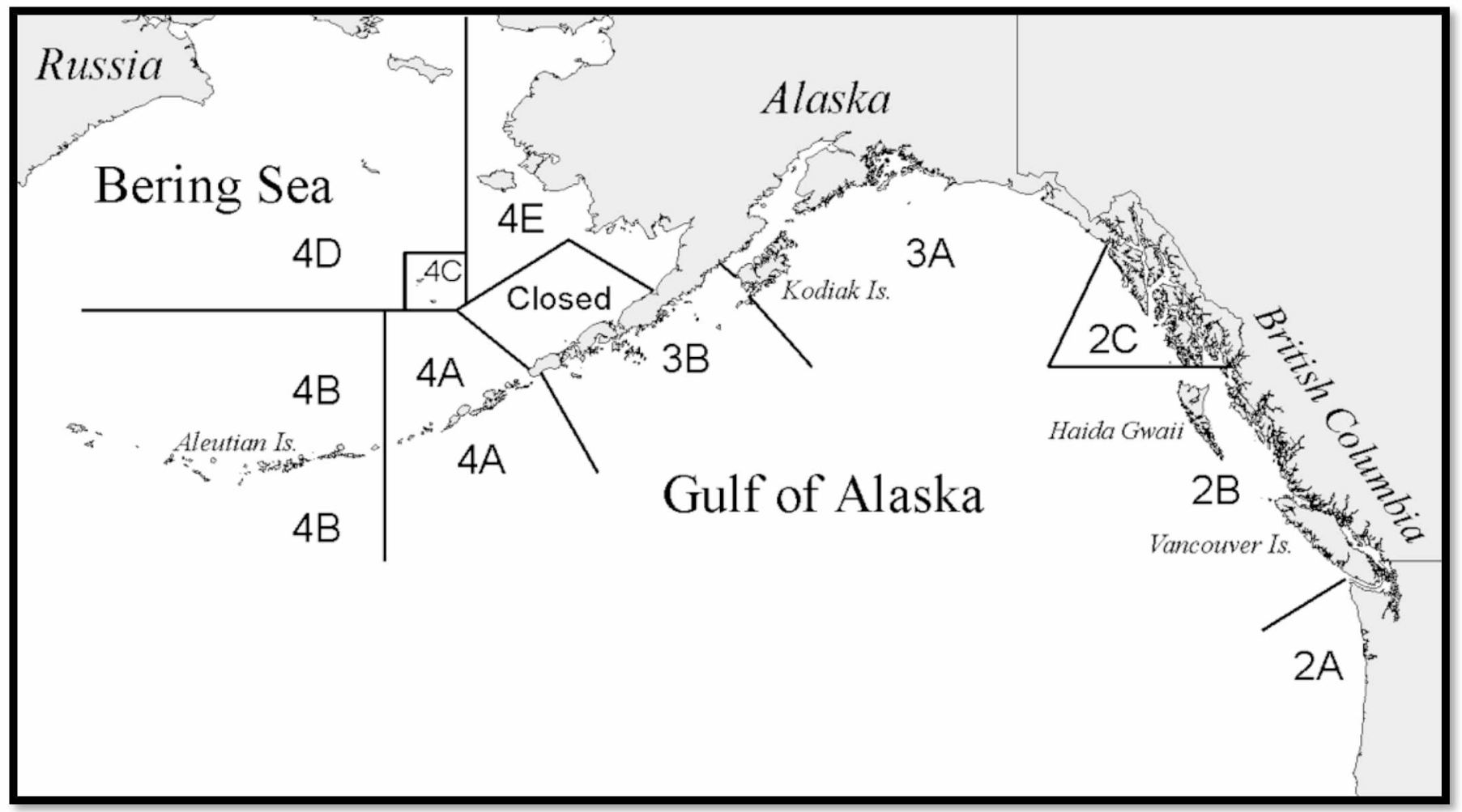

Source: NOAA Fisheries, http://alaskafisheries.noaa.gov/maps/iphc/areas_Irg.gif

Figure 1: The Pacific Northwest map above depicts the migratory span of Pacific Halibut. 


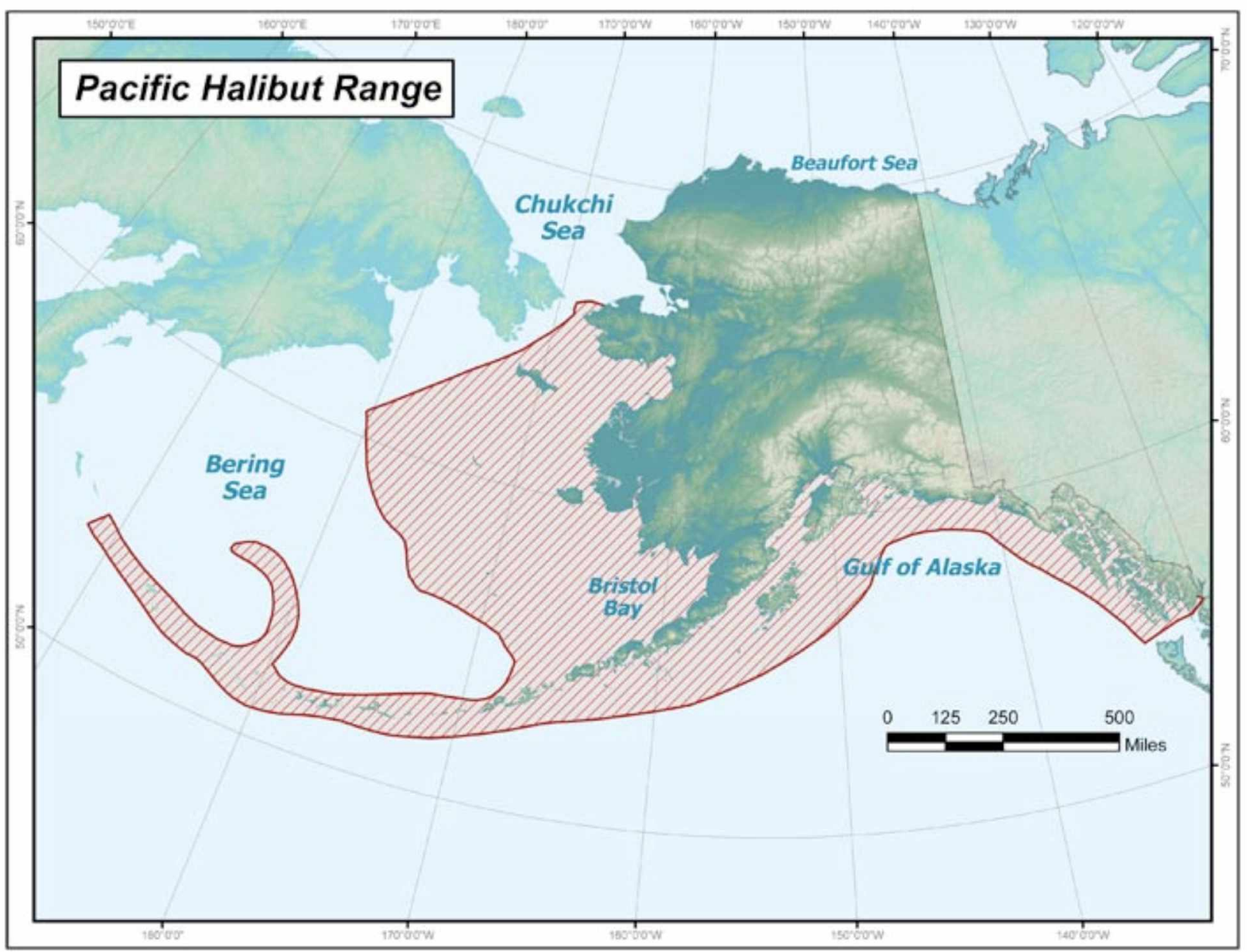

Figure 2. Fishery regulatory areas of the Pacific Northwest, as specified by the International Pacific Halibut Commission (IPHC). The Individual Vessel Bycatch Quotas have been implemented within area 2B of British Columbia since 1996. 


\section{References}

Branch, T. A. (2004). The influence of individual transferable quotas on discarding and fishing behavior in multispecies fisheries. Diss. University of Washington.

Casey, K. E., Dewees, C.M., Turris, B.R., \& Wilen, J.E. (1995). The effects of individual vessel quotas in the British Columbia halibut fishery. Marine Resource Economics, 10, 211-230.

Chapin, S.F., Kofinas, G.P., \& Folke, C. (2009). Principles of Ecosystem Stewardship: Resilience-Based Natural Resource Management in a Changing World. New York, NY: Springer.

Copes, P. (1986). A critical review of the Individual Quota as a device in fisheries management. Land Economics, 62:278-291.

Costello, C., Gaines, S., \& Lynham, J. (2008). Can catch shares prevent fisheries collapse? Science 321, 1678-1681.

Crowley, R. W., \& Palsson, H. (1992). Rights-based fisheries management in Canada. Marine Resource Economics, 7(2), 1-21.

Devido, S. (2006). Review of bycatch management strategies in several fisheries and how they may be applicable to the Gulf of Mexico red snapper and shrimp fisheries. National Oceanic and Atmospheric Association, St. Petersburg, FL.

GSGislason \& Associates Ltd. (2010). Economic impacts from a reduced Groundfish trawl fishery in British Columbia. Canada. BC Ministry of Environment Oceans \& Marine Fisheries Victoria, Vancouver, Canada.

Hardin, G. (1968). The tragedy of the commons. New York.

Hare, S.R. (2013). Assessment of the Pacific halibut stock at the end of 2010. International Pacific Halibut Commission Library. IPHC, n.d. Web. 29. 
$<$ http://www.iphc.int/publications/rara/2010/2010.85.AssessmentofthePacifichalibutstock attheendof2010.pdf $>$.

Jensen, L.S., Koebbe, J., \& Criddle, K.R. (2004), Pooled and individual bycatch quotas: exploring tradeoffs between observer coverage levels, bycatch frequency, pool size, and the precision of bycatch estimates. Economic Research Institute Study Papers. Paper 295. http://digitalcommons.usu.edu/eri/295.

Moloney, D.G., \& Pearse, P.H. (1979). Quantitative rights as an instrument for regulating commercial fisheries. Journal of the Fisheries Research Board of Canada, 36, 859-866.

Panopoulou, E., \& Pittis, N. (2004). A comparison of autoregressive distributed lag and dynamic OLS cointegration estimators in the case of a serially correlated cointegration error. Econometrics, 7, 585-617.

Pesaran, M.H., Shin, Y., \& Smith, R.J. (2001). Bounds testing approaches to the analysis of level relationships. Journal of Applied Econometrics, 16, 289-326.

Pinkerton, E. (2009). Coastal marine systems: conserving fish and sustaining community livelihoods in Chapin, F. S., III, G. P. Kofinas, and C. Folke, editors. Principles of Ecosystem Stewardship: Resilience-Based Natural Resource Management in a Changing World. Springer-Verlag, New York: 241-258.

Schlager, E., \& Ostrom, E. (1999). Property rights regimes and coastal fisheries: an empirical analysis. Polycentric governance and development: readings from the Workshop in Political Theory and Policy Analysis, The University of Michigan Press. 